\title{
TEORIA DE CUSTOS VERSUS TROCAS RELACIONAIS NA DIFERENCIAÇÃO DA OFERTA DE OUTSOURCING
}

THEORY OF COSTS VERSUS RELATIONSHIPS IN THE DIFFERENTIATION OF OUTSOURCING

OFFER

\author{
VERNER LUIS ANTONI ${ }^{1}$ \\ LISIANE CAROLINE RODRIGUES HERMES ${ }^{2}$ \\ RAMADAN SCARTAZZINI AWAD ${ }^{3}$ \\ THAYANE WOELLNER SVIERCOSKI MANOSSO ${ }^{4}$
}

RESUMO: Na busca por vantagens competitivas, as organizações, estrategicamente, delegam a responsabilidade pela execução de algumas de suas atividades a terceiros, o outsourcing. Nesse contexto do Business to Business, este estudo assumiu como objetivos (i) compreender as expectativas das empresas que contratam serviços terceirizados e (ii) identificar como os fornecedores podem diferenciar-se, considerando as expectativas e percepções dos compradores desses serviços. Para tanto, realizou-se uma pesquisa qualitativa e exploratória, com a técnica de múltiplos casos, em empresas que atuam na manufatura de produtos no agronegócio. A principal contribuição do estudo está na constatação de que a teoria baseada em custos de transação explica os motivos para o outsourcing, contudo é a gestão do relacionamento com o cliente o fator determinante para a diferenciação dos fornecedores de serviços de terceirização.

Palavras-chave: Business to business. Outsourcing. Relacionamento interorganizacional.

ABSTRACT: In the search for competitive advantages, the organizations strategically delegate the responsibility for the execution of some of their activities to third parties, outsourcing. In this context of Business to Business, this study has as objectives (i) to understand the expectations of companies that contract outsourced services and (ii) to identify how suppliers can differentiate, considering the expectations and perceptions of the buyers of these services. For this purpose, a qualitative and exploratory research was carried out, using the multiple cases technique, in companies that work in the manufacture of products in agribusiness. The main contribution of the study is the fact that the theory based on transaction costs explains the reasons for outsourcing, but it is the relationship management with the customer that is the determining factor for the differentiation of outsourcing service providers.

Keywords: Business to business. Outsourcing. Interorganizational relationship.

Data de submissão: 06/06/2018. Data de aceite: 05/11/2018. Data de publicação: 17/12/2018.

1 Pós Doutor em Administração - PPGADM/UFRGS; Doutor em Engenharia da Produção - UFSC; Mestre em Administração PPGADM/UFRGS; Professor e Pesquisador do PPGAdm - FEAC - UPF. Endereço: Km 171 - BR 285, São José, 99001-970 Passo Fundo, RS - Brasil - Caixa-postal: 611. e-mail: antoni@upf.br

2 Aluna de Doutorado em Desenvolvimento Regional - UNIJUI; Mestre em Desenvolvimento Regional - UNIJUI;

${ }^{3}$ Aluno de Mestrado em Administração - PPGAdm/FEAC/UPF.

${ }^{4}$ Aluna de Mestrado em Administração - PPGAdm/FEAC/UPF. 


\section{INTRODUÇÃO}

Mesmo sofrendo o impacto de um ambiente de alta complexidade e necessitando de um aprimoramento estratégico constante, estudos em organizações que atuam nos mercados business to business (B2B) têm sido negligenciados ao longo dos anos, quando comparados aos estudos em mercado consumidor (BROWN et al., 2012). Surge, então, a oportunidade para pesquisas teóricas e empíricas que auxiliem as organizações atuantes em mercados B2B a aprofundarem questões estratégicas e operacionais que ampliem sua capacidade competitiva.

Na perspectiva de ampliar a capacidade competitiva organizacional, o outsourcing (terceirização) destaca-se como um importante componente estratégico para aumentar a eficiência e a qualidade nas várias atividades organizacionais (KANG; WU; HONG, 2009; PANDA, 2012). Assim, o outsourcing é visto como uma ferramenta que promete a redução de custos, a melhora da qualidade e da capacidade de otimizar recursos (BARROS, 2006; IPEA, 2015), o que tem, progressivamente, possibilitado o ganho de espaço no mundo corporativo brasileiro para essa prática (FERRUZZI et al., 2011).

A adoção da estratégia do outsourcing, segundo Ferruzzi et al. (2011), tem sido abordada como uma decisão baseada nas teorias da agência, dos custos transacionais e de recursos. Entretanto, esse tipo de estratégia pode ser estudado e compreendido por meio de uma abordagem relacional, visto que perpassa por transações de longo prazo, as quais necessitam para sua construção e sustentação o envolvimento na cultura e nos processos dos compradores por parte dos fornecedores, ou seja, uma abordagem de relações interorganizacionais.

Diante da importância das relações interorganizacionais, Presutti et al. (2017) citam que essas permitem suprir as deficiências institucionais e as condições para as empresas construírem competências específicas para sua inserção competitiva nos mercados, visto que nenhuma organização possui todos os recursos necessários para a sua existência, tornandose importante a relação entre elas (BRITO; MARIOTTO, 2013; VIANA; BARROS; AÑEZ, 2014; HÅKANSSON; SNEHOTA, 2017).

Ao se considerar a necessidade de ampliar os estudos teórico-empíricos em mercados B2B (GRÖNROOS; GRÖNROOS, 2016; GUMMESSON, 2017; HÅKANSSON; SNEHOTA, 2017; PRESSUTTI et al., 2017; LEONIDOU et al., 2018) bem como a importância para a competitividade organizacional dos serviços terceirizados e o papel do relacionamento interorganizacional (GUARNIERI; ALMEIDA, 2015; MCEVILY; ZAHEER; KAMAL, 2017; AGOSTINI; NOSELLA, 2017) no processo de decisão de compra desse tipo de serviço, este estudo objetiva compreender as expectativas das empresas que contratam serviços terceirizados e esclarecer como os fornecedores podem se diferenciar. Para tanto, a abordagem do estudo desenvolvido teve ênfase em compradores de outsourcing, sendo esses inseridos em cadeias de manufatura do agronegócio, as quais têm como característica a alta especificidade dos ativos, exigindo que seus gestores encontrem soluções que, ao mesmo tempo, minimizem as incertezas, reduzam os custos, garantam a qualidade e a confiabilidade do processo, proporcionando algum tipo de vantagem competitiva (PRAHALAD; HAMEL, 1990), visto que a execução de investimentos em ativos específicos torna a terceirização uma opção interessante para indústrias inseridas no agronegócio.

No artigo, além dessa parte introdutória, na segunda seção, apresenta-se o referencial teórico, que aborda mercados $\mathrm{B} 2 \mathrm{~B}$, os relacionamentos interorganizacionais e a estratégia de RGO REVISTA GESTÃO ORGANIZACIONAL | VOL. 11 - № 3 -SET./DEZ. - 2018 
outsourcing. Na terceira seção, é apresentado o método utilizado. Na quarta seção, são descritos e analisados os resultados da pesquisa. Finalmente, são apresentadas as considerações e limitações do estudo, além de sugestões para estudos futuros.

\section{REFERENCIAL TEÓRICO}

\subsection{MERCADOS B2B E OS RELACIONAMENTOS INTERORGANIZACIONAIS}

Durante muitos anos, as trocas foram consideradas pelos pesquisadores apenas como eventos únicos e discretos, não como relacionamentos constantes. Essas trocas são caracterizadas por ganhos imediatos, comunicação limitada e relacionamentos pessoais mínimos (MACNEIL, 1980). Em outro sentido, segundo Peterson (1995), trocas relacionais são longitudinais por natureza, ocorrendo em função da continuidade das transações e do histórico da relação, da aproximação das partes e do planejamento futuro previsto para os participantes do negócio.

Conforme evoluiu o pensamento no marketing B2B, uma nova corrente de pesquisa enfatizou os benefícios que o relacionamento proporciona para as empresas (BIGGEMANN; BUTTLE, 2012). A construção de relacionamentos, conforme Ulaga e Eggert (2006), gera mais resultados, pois ter o status de fornecedor-chave traz mais benefícios às empresas fornecedoras, do que se ater apenas à redução de custos da oferta. De acordo com Geiger et al. (2012), o fator determinante para o sucesso do relacionamento entre empresas é concebido por intermédio do comprometimento entre as partes, em que os participantes podem manter relações porque desejam (dedication-based theory), ou porque eles têm que mantê-las, buscando uma redução dos riscos percebidos (constraint-based theory) (CHANG; WANG; CHIH, 2012; GEIGER et al., 2012).

Nesse contexto, o relacionamento, característica dos mercados B2B (HADJIKHANI; LAPLACA, 2013), remete à interdependência, ao benefício mútuo, à alta adaptação e a um horizonte de médio e longo prazo, podendo atenuar a falta de profissionalização e a baixa qualidade dos fornecedores. Ao mesmo tempo, esse relacionamento permite ao fornecedor entrar na cultura e nos processos e sincronizar-se com as demandas dos seus clientes, representando um esforço do fornecedor que objetiva identificar, construir e manter o relacionamento, trazendo ganhos mútuos, duradouros e de longo prazo (GUMMESSON, 2002).

Autores como Sweeney e Webb (2002), Zaheer e Harris (2005) e Gulati e Nickerson (2008) apresentam outros benefícios do relacionamento, sendo esses definidos como valor simbiótico, psicológico, operacional, social, econômico, estratégico, como o benefício da customização. Bertrand e Lumineau (2016) citam que a variedade de perspectivas, habilidades e percepções de conhecimento são alguns dos benefícios das relações que aumentam a capacidade de resolução de problemas. O conceito de relacionamento, para Gummesson (2017), é constituído por constructos emocionais, que incluem história compartilhada, crenças centrais, objetivos, senso de comprometimento, dependência, auxílio social, intimidade, interesse, respeito e confiança. Especificamente a confiança, pode ser definida como um estado psicológico que compreende a intenção de aceitar a vulnerabilidade baseada em expectativas positivas das intenções ou do comportamento do parceiro (ROUSSEAU, 1989), podendo tornar-se um importante fator para a criação e o desenvolvimento de relacionamento em longo prazo, tendo uma visível participação na melhora dos processos 
interorganizacionais (SCHILKE; LUMINEAU, 2016), tornando-se naturalmente um dos principais sustentáculos do marketing relacional (MCEVILY; ZAHEER; KAMAL, 2017).

Ao se desenvolver um processo de relacionamento, a chance de fidelizar o cliente é maior, sendo que isso depende de informações sobre a cultura e de processos e demandas do mercado do cliente, pois a empresa fornecedora ganha o status de fornecedor-chave (ULAGA; EGGERT, 2006). Ao se construir uma estratégia de relacionamento para diferenciar um fornecedor no mercado, é importante promover o compartilhamento de informações, por meio da abertura de canais de comunicação que aprimorem a troca de informações entre os parceiros, gerando inteligência de mercado e o intercâmbio de ideias bem como promovendo a inovação conjunta (BIGGEMANN; BUTTLE, 2012).

\subsection{OUTSOURCING}

A prática da terceirização, do inglês outsourcing, fundamenta-se em diferentes processos de articulações entre empresas, seja de um ponto de vista técnico, econômico, ou até mesmo numa perspectiva jurídica (BUSI; MCIVOR, 2008). A terceirização pode ser caracterizada como um processo por meio do qual uma organização (contratante), alinhada com a sua estratégia, contrata outra (subcontratada), na perspectiva de um relacionamento mutuamente benéfico, de médio ou longo prazo, para o desempenho de uma ou várias atividades, nas quais a primeira não pode desempenhar ou não é conveniente que o faça, sendo a segunda tida como especialista (PLUGGE; BOUWMAN; MOLINA-CASTILLO, 2013).

A prática do outsourcing tem permitido às organizações garantir a flexibilidade necessária para competir num ambiente caracterizado por uma concorrência crescente, baseada em competências estratégicas, manutenção de vantagem competitiva sustentável, diferenciação, ciclos de produção cada vez mais curtos, orientação para o cliente e a liderança por meio de custos (BUSI; MCIVOR, 2008; PATIL; PATIL, 2014). Logo, o processo de terceirização nas indústrias pode ser visto como uma nova forma de agregar valores aos serviços, à inovação e à transformação, por intermédio de organizações mais competitivas e com maior capacidade de inserção de seus produtos para os clientes (OSHRI; RAVISHANKAR, 2014).

Para o desenvolvimento de uma terceirização eficaz, tem-se como base a constituição de alianças, fusões e cooperações entre as organizações, configurando-se como uma estratégia baseada em tecnologias e equipamentos propostos pelo mercado (HUANG; CHINA, 2014). Ressalta-se que os gestores também podem buscar a terceirização como meio de crescimento, alavancando sua base de fornecimento para atender às variações da demanda do mercado, pois determinadas demandas não poderiam ser atingidas isoladamente (BREWER; ASHENBAUM; OGDEN, 2013).

Entre as vantagens, podem-se identificar o know-how que é gerado e que pode constituir uma importante fonte de inovação e mudança. A possibilidade de os parceiros poderem fazer "benchmarking" e tomar contato com algumas best practices, para, com isso, identificar fraquezas e oportunidades permite aprimorar processos de gestão, dado que os parceiros se revelam, muitas vezes, mais exigentes do que os próprios clientes finais (COSTA; BARREIROS, 2013). O outsourcing está associado à redução de custos (face às economias de escala resultantes) na tarefa de providenciar competências inovadoras (que de outra forma seriam impossíveis de alcançar) como aumentar a rentabilidade, partilhar riscos, obter níveis de serviços desafiantes e ter uma visão de futuro (ENSSLIN et al., 2015).

RGO REVISTA GESTÃO ORGANIZACIONAL | VOL. 11 - № 3 -SET./DEZ. - 2018 
Três critérios são utilizados pelos compradores na decisão de adotar uma estratégia de terceirização: a análise econômica, a análise de competências essenciais e a análise de custos de transação (GUTWALD, 1996). A análise econômica avalia o benefício ou não de terceirizar. Para tanto, torna-se importante a utilização da ferramenta de viabilidade econômica: o custo. Nessa abordagem, compara-se o custo de fabricação com o custo de aquisição de um terceirizado (GUTWALD, 1996).

$\mathrm{Na}$ análise de competências essenciais, a organização deve verificar se o seu diferencial e suas habilidades estão em um determinado segmento, sendo mais viável então terceirizar a produção, o que retrata o foco dos esforços e dos investimentos da empresa. As competências podem ser classificadas segundo dois critérios, a competência relativa ao mercado, que compara a capacidade da empresa e dos demais concorrentes no que se refere a custos, qualidade e processo; e a competência estratégica, a qual verifica se a atividade poderá ou não a diferenciar em relação aos concorrentes, aumentando, assim, o valor percebido pelo cliente (PRAHALAD; HAMEL, 1990).

Numa transação, o custo ocorre toda vez que um bem ou serviço é transferido para uma interface tecnologicamente separada, ou seja, os custos de transação são aqueles ocorridos quando os agentes dispostos a efetivar a transação, comunicam-se e trocam informações, que não se resumem a preços (WILLIAMSON, 2000). Uma série de estudos examinam a terceirização em uma perspectiva estratégica, focando os fatores de terceirização e como as decisões de terceirização são aprimoradas para ajudar a tomada de decisões estratégicas (SANDERS et al., 2007; KROES; GHOSH, 2010; DIAZ-MORA; TRIGUERO-CANO, 2012).

Uma das motivações mais comuns por trás das decisões de terceirização é a redução de custos (ARIAS-ARANDA; BUSTINZA; BARRALES-MOLINA, 2010; MUKHERJ; RAMACHANDRAN, 2007; YU; LINDSAY, 2011). A terceirização para redução de custos assume, em grande parte, a existência de parceiros da cadeia de suprimentos que possuem economias de escala de produção significativas, alavancagem de volume com múltiplos fornecedores ou eficiências operacionais como agentes especializados do mercado (JENSEN; PEDERSEN, 2012; WEIGELT; SAKAR, 2012). Além de encontrar um fornecedor de baixo custo, os produtos ou serviços podem ser terceirizados para um fornecedor de qualidade superior com a intenção de reduzir o custo geral da qualidade da empresa compradora (KUMAR; KOPITZKE, 2008; DIAZ-MORA; TRIGUERO-CANO, 2012).

De acordo com Hätönen e Eriksson (2009), o outsourcing tem como seu principal objetivo a redução dos custos operacionais, pois, ao reduzi-los, as organizações ganham a capacidade de melhorar a eficiência operacional, aumentam o retorno sobre os ativos e melhoram a rentabilidade. Lacity, Khan e Willcocks (2009) assim como Prado (2009) acrescentam que as empresas terceirizam principalmente para reduzir custos e recursos e concentrar os últimos em estratégicas da organização, possibilitando que se alcance economias de escala, o que se configura como uma ótima estratégia de negócio.

Outra motivação para contratar um terceirizado, vincula-se à importância estratégica de a empresa se concentrar na sua atividade foco, deixando para terceiros as atividades de apoio e que não estejam relacionadas com sua competência essencial, o que, segundo Prahalad e Hamel (1990), proporciona vantagem competitiva, por vir a ser uma solução encontrada pelos gestores que pode representar redução de custos e garantir qualidade e confiabilidade aos processos. Nessa mesma linha, Tallon (2008) indica que a terceirização 
ocorre no momento em que as organizações buscam um especialista em determinada atividade, evitando a realização de investimentos e a aquisição de know-how, que dependem de uma especialização que não é sua core competence.

As competências essenciais envolvem tarefas avançadas ou baseadas no conhecimento que separam as empresas dos concorrentes (BOLUMOLE, 2003; JENSEN; PEDERSEN, 2012), podendo incluir produção intensiva de competências, construção de relacionamento com clientes, inteligência de mercado e integração de sistemas (EDVARDSSON, 2011; YU; LINDAY, 2011; DIAZ-MORA; TRIGUERO-CANO, 2012; JENSEN; PEDERSEN, 2012). As organizações podem, portanto, aumentar o valor que elas oferecem ao derrubar atividades que não suportam essas competências (FILL; VISSER, 2000; HSIAO et al., 2010; ZACHARIA; SANDERS; NIX, 2011). A terceirização permite que as organizações busquem recursos e concentrem mais atenção em sua core competence, permitindo que provedores externos cuidem de outras atividades (MUKHERJ; RAMACHANDRAN, 2007; NAYAK; SINHA; GUIN, 2007; JENSEN; PEDERSEN, 2012).

Contudo, quando as empresas terceirizam sua core competence, existe uma grande chance de perder o contato com o know-how que permite a inovação ou a capacidade de se adaptar às mudanças das condições de mercado (EDVARDSSON, 2011; WEIGELT; SAKAR, 2012). A terceirização dessas atividades principais e distintivas pode resultar em perdas significativas da singularidade de valor agregado da empresa (KOTABE et al., 2012), o que, no pior cenário, resulta em uma empresa vazia que não tem mais recursos ou capacidades competitivas (WEIGELT; SAKAR, 2012). Percebe-se uma relação entre a decisão de terceirizar e o crescimento da demanda de mercado das empresas. Essa contingência conduz à necessidade de contratar terceirizados para que as empresas possam atender às variações de demanda, o que não seria possível de se fazer isoladamente sem utilizar esse tipo de estratégia (BREWER; ASHENBAUM; OGDEN, 2013).

Segundo Delgado (2013), na terceirização, dissocia-se a relação econômica de trabalho da relação jurídico-trabalhista que lhe seria correspondente, inserindo o trabalhador no processo produtivo do tomador de serviços sem que se estendam a esse os laços jurídicos e trabalhistas, que se preservam fixados com uma entidade interveniente. A terceirização, então, provoca uma relação trilateral, o prestador de serviço, que realiza suas atividades materiais e intelectuais na empresa tomadora de serviços; a empresa terceirizada, que contrata o empregado, firmando com ele os vínculos jurídicos trabalhistas pertinentes; a empresa tomadora de serviços que recebe a prestação de labor, mas não assume a posição clássica de empregadora do trabalhador envolvido, diminuindo seus riscos jurídicos (BARROS, 2006; MIRAGLIA, 2008; DELGADO, 2013).

Plugge, Bouwman e Molina-Castillo (2013) sugerem que sejam analisados fatores como a frequência, a incerteza e a especificidade do ativo para a terceirização. Para os autores, esse estudo envolve, no mínimo, uma convergência de três ciências sociais aplicadas: direito, economia e administração. À vista disso, considera-se que esse tipo de aliança tem foco em ações de longo prazo, o que pode ser alterado de acordo com o volume, com a complexidade das operações envolvidas com a facilidade ou não de se captar e desenvolver fornecedores eficientes (CHOPRA; MEINDL, 2002).

A terceirização na organização é uma ação caracterizada como uma técnica administrativa, que se baseia nos processos de gestão estruturais da indústria, provinda de meios culturais, procedimentos e sistemáticas por meio de controles com o objetivo de 
alcançar melhores resultados da empresa em sua atividade principal (PATIL; PATIL, 2014). Assim, relacionamentos coesos podem aprimorar o desenvolvimento de novos processos e tecnologias e agregar valor aos clientes dos compradores de serviços terceirizados, graças à redução de custos e ao aumento da flexibilidade necessária para competir num ambiente de crescente concorrência, aos ciclos de produção mais curtos, à orientação para o cliente e à busca por custos cada vez menores (BUSI; MCIVOR, 2008; PATIL; PATIL, 2014).

Partindo dos autores apresentados, referenda-se que o estudo aborda a importância e o benefício do relacionamento para a oferta e a tomada de decisão de compra de serviços terceirizados, podendo vir a ser uma forma de diferenciação por parte dos fornecedores inseridos nesse mercado.

\subsection{TEORIA DE CUSTOS DE TRANSAÇÃO}

Pode-se inferir por transação as relações entre clientes, fornecedores, funcionários da organização, governo, entre outros atores, realizadas segundo contratos formais ou informais. Tal abordagem postula que estruturas organizacionais, tal como firma, mercado e redes, são o resultado da busca pela minimização dos custos por parte dos agentes econômicos (PONDÉ; FAGUNDES; POSSAS; 1997). Em contraponto à teoria relacional, o enfoque proposto por Ngwenyama e Bryson (1999) a Teoria dos Custos de Transação (TCT) analisa e identifica os custos envolvidos na transação, que podem ser significativos, dependendo do tipo de serviço ou produto em questão.

Complementando a ideia sobre a TCT, pode-se afirmar que quanto maior for a dependência que uma organização tem dos recursos de outra, maior será o tipo de controle que essa organização procurará exercer sobre a outra, então, quanto maior for a dependência de recursos entre organizações (interdependência), maiores serão os custos de transação (PFEFFER; SALANCICK, 2003).

Para Pfeffer e Salancick (2003), a interdependência existe quando não se pode controlar todos os recursos necessários para uma ação desejada. Além disso, a interdependência pode se dar (i) nos resultados, como a que ocorre entre organizações concorrentes; e (ii) nos comportamentos. A interdependência provoca a incerteza e, concomitantemente, medidas para reduzir essa incerteza, como encontrar outro fornecedor. A solução para os problemas de interdependência é uma maior coordenação e controle recíproco sobre recursos, isto é, aumentando a interdependência comportamental (PEFFER; SALANCICK, 2003).

Dessa maneira, pode-se entender os custos de transação como o dispêndio de recursos econômicos para planejar, adaptar e monitorar as interações entre os agentes, o que garante que o cumprimento dos termos contratuais se dê de maneira satisfatória para as partes envolvidas. Assim, os custos de transação representam os custos para realização dos negócios (FAGUNDES, 1997) e são, em geral, difíceis de quantificar (WILLIAMSON, 1985).

De um modo geral, a TCT dedica-se a compreender as transações econômicas e explora as vantagens contingentes dos arranjos organizacionais, buscando responder, por exemplo, porque algumas transações são internas e outras externas às organizações. O foco está nos custos para conduzir as transações no mercado e nos mecanismos existentes para reduzir tais custos (COASE, 1937; WILLIAMSON, 1985). 


\section{MÉTODO}

Para atender aos objetivos estabelecidos na pesquisa, utilizou-se uma abordagem qualitativa e exploratória, que, conforme Malhotra (2001) pretende possibilitar uma compreensão aprofundada com relação ao problema abordado.

A técnica utilizada para obter os dados foi a de entrevistas em profundidade, a qual permite descobrir motivações, crenças, atitudes e sensações subjacentes sobre um tópico (MALHOTRA, 2001). Para as entrevistas, fez-se uso de um roteiro semiestruturado, elaborado com base na revisão da teoria, o qual contemplou construtos referentes a relacionamento interorganizacional, motivos para a terceirização nas organizações bem como atributos para a escolha e a diferenciação de fornecedores de serviços terceirizados. No roteiro, foram utilizadas onze perguntas norteadoras e, quando necessário, foram feitas mais indagações ao entrevistado, a fim de ampliar o entendimento da percepção e da opinião desse sobre o tema pesquisado. Todas as entrevistas foram gravadas para a transcrição e a análise posterior.

Este estudo é caracterizado por múltiplos casos. Para Gil (2010), a utilização de múltiplos casos consegue proporcionar evidências inseridas em contextos diferentes. As empresas abordadas foram identificadas a partir da base de dados de uma empresa que atua no segmento de serviços terceirizados nas indústrias que abatem e manufaturam nas cadeias de aves e suínos e fabricantes de equipamentos para indústrias dessas cadeias. O Quadro 1 apresenta a descrição dos casos estudados.

Quadro 1 - Descrição dos casos

\begin{tabular}{|l|l|l|}
\hline Casos & \multicolumn{1}{|c|}{ Descrição das empresas } & \multicolumn{1}{|c|}{$\begin{array}{c}\text { Cargos dos } \\
\text { entrevistados }\end{array}$} \\
\hline Caso 1 & $\begin{array}{l}\text { Atuação no mercado de alimentos em } 110 \text { países, sendo uma das principais } \\
\text { exportadoras de proteína animal em nível mundial, com } 100 \text { mil funcionários, } 47 \\
\text { fábricas no Brasil e onze Exterior. Portfólio de produtos com cerca de cinco mil itens. }\end{array}$ & $\begin{array}{l}\text { Negociador } \\
\text { Coorporativo } \\
\text { de Suprimentos }\end{array}$ \\
\hline Caso 2 & $\begin{array}{l}\text { Unidade de abate de animais e produção de alimentos da empresa descrita no Caso } \\
\text { 1, localizada no Oeste de Santa Catarina. }\end{array}$ & $\begin{array}{l}\text { Coordenador } \\
\text { Administrativo }\end{array}$ \\
\hline Caso 3 & $\begin{array}{l}\text { Líder mundial na produção de silos para armazenagem, secadores e transportadores } \\
\text { de grãos. Fábricas nos Estados Unidos, Canadá, Malásia, China e Brasil. A Unidade } \\
\text { abordada localiza-se no Norte do Rio Grande do Sul. }\end{array}$ & $\begin{array}{l}\text { Supervisora de } \\
\text { RH }\end{array}$ \\
\hline Caso 4 & $\begin{array}{l}\text { Cooperativa de alimentos formada por 14 cooperativas filiadas, com mais de 70 mil } \\
\text { famílias associadas e 34 mil funcionários. Atua na industrialização e comercialização } \\
\text { animal; } \\
\text { Apresenta unidades industriais, comerciais, granjas e distribuidoras instaladas em } \\
\text { território nacional. Localiza-se no Oeste de Santa Catarina. }\end{array}$ & $\begin{array}{l}\text { Analista de } \\
\text { Projetos Sênior } \\
\text { e de RH }\end{array}$ \\
\hline Caso 5 & $\begin{array}{l}\text { Unidade para abate de animais e produção de alimentos da empresa descrita no } \\
\text { Caso 4. Localiza-se no Norte do Rio Grande do Sul. }\end{array}$ & Gerência de RH \\
\hline Caso 6 & $\begin{array}{l}\text { Atua nos segmentos de grãos, insumos, industrialização de soja, rações, avícola e de } \\
\text { supermercado, quadro funcional de } 5 \text { mil colaboradores. Atua no mercado nacional } \\
\text { e internacional. Localiza-se no Planalto Médio do Rio Grande do Sul. }\end{array}$ & $\begin{array}{l}\text { Gerência de } \\
\text { Compras }\end{array}$ \\
\hline
\end{tabular}

Fonte: Elaborado pelos autores (2018).

Dentre os serviços terceirizados ofertados por essa empresa, estão os de asseio e conservação, higienização, apanho de aves (recolhimento manual de aves nas granjas), segurança privada e monitoramento. Essa empresa atua na região Sul do Brasil. 
Para a escolha dos casos foram definidos os seguintes critérios: o porte da empresa (faturamento), marca com atuação internacional e nacional; inserção no segmento industrial do agronegócio.

Os dados primários foram sistematizados de acordo com os objetivos da pesquisa, para então proceder à análise qualitativa, a qual permitiu descrever e contextualizar de maneira que tornou-se possível interpretar o ambiente ou as pessoas que produziram o texto em seus próprios termos, em vez de tomar por base medidas pré-definidas e hipóteses (SCHUTT, 2012). Dessa forma, foi possível identificar categorias importantes de dados, conforme padrões e relações. A técnica utilizada para analisar e interpretar as entrevistas foi a análise de conteúdo, a qual permite classificar palavras, frases, e outras categorias de conteúdos (ROESCH, 2005).

Para a análise, foram consideradas duas categorias de dimensões, as relacionadas às motivações para contratar um fornecedor de outsourcing (custos operacionais, concentrar-se na atividade foco do negócio, riscos legais e custos trabalhistas, gestão conjunta de projetos e custos) e a relacionada à forma como ocorre a diferenciação entre fornecedores (profissionalização na gestão e qualidade do serviço contratado, especialização na atividade a ser terceirizada, desenvolvimento conjunto de inovação tecnológica e processos e turnover). Finalmente, os conteúdos das entrevistas e as dimensões identificadas foram relacionados e interpretados, utilizando-se o referencial teórico que sustenta o estudo.

\section{RESULTADOS}

A seguir, são apresentadas as descrições e as análises das entrevistas realizadas.

\subsection{DESCRIÇÃO DOS CASOS ESTUDADOS}

\subsubsection{Caso 1}

A empresa relatada no Caso 1 tem como principais atividades terceirizadas as de asseio e conservação, higienização, movimentação de mercadorias, apanho de aves e monitoramento eletrônico de segurança. $O$ gestor entrevistado destaca que a empresa possui mapeados todos os processos terceirizados, o que contribui para um melhor gerenciamento da qualidade dos serviços prestados pelos fornecedores. Segundo o entrevistado, conforme cresce a necessidade de terceirização, aumentam as operações incorporadas, que passam a ser mais complexas, o que se torna uma ameaça aos atuais modelos de gestão das empresas estabelecidas no mercado de terceirização. Nas palavras do entrevistado:

\footnotetext{
Estas empresas são pouco profissionais, o que gera dificuldade para a integração nos processos do cliente e as coloca a mercê das políticas governamentais com o setor. No entanto, surge uma oportunidade à profissionalização dos fornecedores, com destaque a análise e desenvolvimento conjunto de processos. [...]. De cada dez, quatro fornecedores são profissionais, o modelo de gestão dos fornecedores, na sua maioria é ineficiente, muitos começam bem, porém entram demais na sua própria operação, se fecham na empresa, esquecem o cliente. O maior gargalo dos fornecedores está nas pessoas e na retenção da mão de obra (turnover).
}

Ele salienta que um fornecedor que conseguir compreender as necessidades do cliente e que se dedicar a entender e se inserir nos processos da empresa que atende tem muito a ganhar. Assim, declara "vamos pagar mais para um fornecedor que seja mais profissional e saiba usar a tecnologia em favor da redução de custos".

RGO REVISTA GESTÃO ORGANIZACIONAL | VOL. 11 - № 3 -SET./DEZ. - 2018 
Como principais atributos para a contratação de serviços terceirizados, o entrevistado cita a gestão conjunta de processos e custos. Entende, ainda, que a tendência da terceirização será um caminho sem volta e aponta também uma grande oportunidade para os fornecedores relacionada com a flexibilização operacional. Em suas palavras:

Aqueles que puderem terceirizar o farão, o risco do encargo social é alto $70 \%$ a $85 \%$,
e as margens são menores. O grande negócio é o serviço temporário, mão de obra
temporária é onde tem a maior margem, só tem que conhecer o processo do cliente.

Um elemento que gerou satisfação na contração, conforme exemplificado pelo entrevistado, foi o fato de um fornecedor apresentar um estudo de cronoanálise do processo a ser terceirizado, todavia, a principal insatisfação com a maioria dos fornecedores está relacionada ao elevado turnover de colaboradores, o que impacta na eficiência da operação terceirizada.

O entrevistado explica que devido à empresa ter muitas filiais no país, a escolha de um fornecedor considera a capilaridade desse com as regionais e unidades no qual irá atuar. Ainda, para a contratação são considerados trâmites internos, tendo como primeiro passo uma solicitação no mercado fornecedor, uma Requisição de Informação (RI), pela qual são levantados dados de faturamento, evolução, situação legal e averiguado quem são os clientes atuais do fornecedor, bem como seu know-how na atividade ou no processo a ser terceirizado; em seguida é elaborado um score card para cada empresa ofertante e, então, é definido um ponto de corte. Finalmente, é feita uma Requisição Final de Cotação (RFQ).

$\mathrm{Na}$ visão do entrevistado, existe espaço no mercado para novos fornecedores, desde que esses desenvolvam processos em conjunto com o cliente, "os fornecedores têm que ter visão de processo, não adianta só colocar cabeças (pessoas) no processo terceirizado, até porque estes fornecedores são empresas de serviços em processos de logística".

\subsubsection{Caso 2}

Nesse caso, as atividades terceirizadas pela empresa são de asseio e conservação, higienização, apanho de aves, restaurante, construção civil, manutenção do prédio e das máquinas, academia e atendimento ambulatorial.

As perspectivas em relação ao mercado de terceirização são positivas, contudo, os fornecedores necessitam melhorar a forma pela qual oferecem seus serviços, considerando processos automatizados. Para o entrevistado:

\footnotetext{
Um problema latente é a escassez da mão de obra neste segmento. As oportunidades que os fornecedores de serviços terceirizados têm, se relacionam a busca de melhoras nos processos para suprir a mão de obra, por exemplo: poucas empresas possuem o processo automatizado [...] As empresas que fornecem serviços terceirizados deveriam avançar na melhoria dos processos do cliente, pois isto reflete diretamente na redução de custos, que é um benefício que os compradores buscam com a terceirização. O setor sofre com a falta de mão de obra qualificada. O fator diferencial para as empresas terceirizadas é o desenvolvimento de processos automatizados no setor de limpeza.
}

Os principais atributos para a contratação de um terceirizado são: preço, qualidade e certificações. A empresa tem um programa que contempla saúde, segurança e meio ambiente, o que exige que os fornecedores sigam essas normas e políticas da empresa. 0 entrevistado aponta como tendência a concentração em poucos fornecedores de serviços 
terceirizados com grande capacidade, pois somente assim é possível padronizar os processos e a qualidade dos serviços.

\subsubsection{Caso 3}

A empresa estudada tem contratos de serviços terceirizados nas atividades de asseio e conservação, segurança privada, frota e alimentação. Além das atividades relacionadas a serviços, terceiriza, também, operações do setor produtivo como corte, dobra, galvanização e pintura.

A busca por terceirização de serviços está relacionada ao foco de mercado no qual atua a empresa contratante. Para a gestora entrevistada, a empresa tem "a intenção de terceirizar parte da Área de RH, sendo influenciada principalmente pela folha de pagamento".

Como principais oportunidades para a contratação de fornecedores do serviço de terceirização, a entrevistada cita a contratação de pessoas para serviços que a empresa não tem especialidade, que não são o foco da empresa, devido à dificuldade imposta pela burocracia no que se refere a questões fiscais e trabalhistas.

Com relação aos atributos para a contratação de um fornecedor, segundo a entrevistada, "primeiro é observado o perfil de trabalho do fornecedor, se realmente é capaz de prestar o serviço da maneira adequada, no nível que a sua empresa precisa receber. Após essa definição, é analisado o preço do serviço, quanto a empresa cobrará, contudo, destaca que nem sempre o preço é o atributo mais importante para a seleção de um fornecedor".

A entrevistada salienta que o fator de diferenciação para um fornecedor está relacionado à sua capacidade de atender a várias especialidades. Em suas palavras, "seria ótimo porque iria permitir à empresa reduzir o número de fornecedores, tornando mais fácil para a contratante ter controle sobre todos os serviços que são prestados".

\subsubsection{Caso 4}

No Caso 4, a empresa contrata serviços terceirizados nas atividades de asseio e conservação, higienização, movimentação de mercadorias, apanho de aves, segurança privada e monitoramento.

Para a gestora entrevistada, a terceirização é um mercado que ainda está em expansão, contudo, acredita que o crescimento é limitado ao investimento de novas unidades ou a instalação de outras empresas em se tratando do seu segmento de mercado. Para a entrevistada:

\footnotetext{
Talvez uma oportunidade seja ganhar em concentração de atividades e foco, o que poderia ser feito é um centro de serviços compartilhados. A principal oportunidade no setor é o investimento em serviços especializados. O desafio para os fornecedores se relaciona à manutenção da qualidade do serviço oferecido.
}

$\mathrm{Na}$ contração de um terceirizado, a sua empresa considera uma lista de documentos que o fornecedor deve entregar e de requisitos que precisa preencher, o que é solicitado pelo setor de RH. Entretanto, a decisão final é do setor de compras. Os dois fatores que diferenciam os fornecedores são atendimento e qualidade, como enfatiza a entrevistada.

Um ponto forte para uma empresa prestadora de serviços é oferecer antes de qualquer coisa a documentação, ou seja, o atendimento das exigências legais. [...] 0 diferencial está no atendimento, pois hoje todos têm qualidade, hoje é obrigação, é 
o mínimo, agora o diferencial está na gestão do negócio, no atendimento, rapidez e no relacionamento.

\subsubsection{Caso 5}

Os serviços terceirizados pela empresa são de restaurante, lavanderia, vigilância, portaria e desinsetização. Como perspectivas de mercado, destaca-se a importância do fornecedor para a redução dos custos de sua empresa. Contudo, isso deve acontecer sem perder a qualidade do serviço prestado e o respeito à cultura da empresa contratante. Nas palavras da entrevistada, "a terceirização veio para ficar, não vejo outra forma. É uma questão do foco, se sua empresa quiser dar conta de tudo que envolve a organização, não conseguirá trabalhar de forma adequada".

Há a preocupação da oferta de um serviço de qualidade, atuando em sintonia com o cliente, na dimensão cultural e operacional, o que perpassa pela rotatividade de funcionários dos fornecedores. Como evidencia-se na sua fala a seguir:

\footnotetext{
Prestar um bom serviço, além de ter uma aproximação para tentar trabalhar mais sintonizada, trabalhar o mais próximo possível da cultura da empresa em que se está atuando. Diante disto, um ponto fraco das empresas de terceirização é a alta rotatividade de funcionários.
}

Dentre os atributos de destaque para a escolha de um terceirizado, primeiramente está a seriedade da empresa, o que é verificado pela documentação correta e pela credibilidade dessa no mercado. O outro atributo é o preço, contudo, esse não é um fator determinante para a decisão. Ainda foi destacada a agilidade de resposta às demandas do cliente, fator que gera a percepção de qualidade.

A decisão de escolha por um serviço terceirizado se dá após um levantamento de informações sobre as empresas fornecedoras. Ademais, o tamanho e a cultura das empresas que terceirizam influenciam nessa decisão. Assim, a entrevistada afirma que:

\footnotetext{
Quanto maior ela fica (sua empresa), mais difícil de manter diversos serviços próprios; razão que levou a empresa a terceirizar, ainda a necessidade em focar nos seus processos, no produto final. São terceirizados serviços que você acaba se desgastando, perdendo tempo, esforço e que não é o teu foco, que é a produção.
}

\subsubsection{Caso 6}

A empresa tem contratos de terceirização nas atividades de asseio e conservação, higienização, segurança privada e monitoramento. A maior parte de serviços terceirizados é na parte Metalomecânica, que são serviços dentro da própria fábrica, atividades que a equipe de manutenção não consegue executar durante o expediente.

O gerente de compras entrevistado afirma que uma perspectiva para o setor está no crescimento da utilização das empresas de contratos de terceirização. A empresa em questão optou pela terceirização porque estava com uma situação de muitas horas extras.

\footnotetext{
A grande vantagem em terceirizar é que muitas vezes pode acontecer do funcionário deixar coisas acumuladas, para depois ele mesmo vir fazer e ganhar hora-extra. Isso é uma coisa que a gente cortou justamente por essa situação.
}

Quanto ao principal atributo para a escolha de uma terceirizada, o entrevistado salienta a qualidade alinhada ao preço do fornecedor. E afirma "procuramos sondar a empresa, ver onde já fez trabalhos, se foram trabalhos com dificuldade e, em cima disso, se trabalha preço. Preço também é bastante considerado". 
Como fator de diferenciação, vem a capacidade operacional do fornecedor em atender a demandas da empresa. O entrevistado declara que "quando se tratam de projetos grandes, a capacidade da empresa em dar condições favoráveis de pagamento, e projetos pequenos, o que diferencia é a qualidade do serviço, prazo de entrega e se o pessoal tem todas as especificações de segurança". Ainda, quando indagado se há espaço para novos fornecedores no mercado de terceirizados, obteve a assertiva de que existem oportunidades:

Digamos que hoje nós temos pouca gente capacitada para fazer o serviço. Tem
pessoas, mas poucas capacitadas. Então, ou tem empresas enormes ou pessoas com
pouca capacitação. Tem espaço na parte Elétrica e Metalomecânica. A minha política
é de desenvolver o fornecedor, ajudar ele a se especializar, é um ganha-ganha, a
gente ajuda o fornecedor a desenvolver sua capacidade para continuar como
prestador de serviço.

O entrevistado destaca que os serviços contratados não são contínuos. Com exceção dos contratos de segurança, o maior volume se concentra na manutenção e na reforma, pois os riscos impetrados pela legislação trabalhista vigente no País são muito altos.

\subsection{ANÁLISE E DISCUSSÃO DOS CASOS ESTUDADOS}

No Quadro 2, estão sintetizados os pontos mais importantes identificados nos casos estudados.

Quadro 2 - Motivadores da terceirização e diferenciação entre fornecedores

\begin{tabular}{|l|l|}
\hline \multicolumn{1}{|c|}{ Motivadores da terceirização } & \multicolumn{1}{|c|}{ Diferenciação entre fornecedores } \\
\hline Menores custos operacionais para o comprador. & $\begin{array}{l}\text { Profissionalização na gestão, relação preço/qualidade } \\
\text { do serviço contratado. }\end{array}$ \\
\hline $\begin{array}{l}\text { Contratação de serviços especializados para a } \\
\text { empresa concentrar-se na sua atividade de foco. }\end{array}$ & $\begin{array}{l}\text { Especialização na atividade a ser terceirizada, por meio } \\
\text { da gestão conjunta de custos e processos, e culturas } \\
\text { semelhantes. }\end{array}$ \\
\hline $\begin{array}{l}\text { Questões legais que geram riscos e custos } \\
\text { trabalhistas. }\end{array}$ & $\begin{array}{l}\text { Desenvolvimento conjunto de inovação tecnológica e } \\
\text { de processos. }\end{array}$ \\
\hline Gestão conjunta de processos e custos. & Baixo turnover da mão de obra ofertada. \\
\hline
\end{tabular}

Fonte: Elaborado pelos autores (2018).

Dentre os motivadores da terceirização encontrados no estudo, os custos operacionais menores para o comprador é uma das motivações mais comuns por trás das decisões de terceirização (MUKHERJI; RAMACHANDRAN, 2007; ARIAS-ARANDA; BUSTINZA; BARRALESMOLINA, 2010; YU; LINDSAY, 2011). Para redução de custos, é necessária a existência de parceiros da cadeia de suprimentos que têm economias de escala de produção significativas, alavancagem de volume com múltiplos fornecedores ou eficiências operacionais como agentes especializados do mercado (JENSEN; PEDERSEN, 2012; WEIGELT; SAKAR, 2012). Além de encontrar um fornecedor de baixo custo, os produtos ou serviços podem ser terceirizados para um fornecedor de qualidade superior com a intenção de reduzir o custo geral com qualidade para a empresa compradora (KUMAR; KOPITZKE, 2008). Isso vem ao encontro do atributo diferenciador entre fornecedores identificado no estudo que é "a profissionalização na gestão e a relação preço/qualidade do serviço contratado".

A terceirização para redução de custos também pode reduzir os investimentos fixos em processos e instalações internas (DIAZ-MORA; TRIGUERO-CANO, 2012; KOTABE et al., 
2012) e permitir que o capital seja investido em áreas de maior produtividade dentro da empresa. A terceirização também pode ser uma fonte de dinheiro para as organizações à medida que os ativos são transferidos para os fornecedores (ELMUTI; KATHAWALA; MONIPPALLIL, 1998).

A terceirização de serviços inegavelmente tem no seu principal objetivo a parte econômica. Para implementar a estratégia de terceirização nas suas empresas, os compradores realizam essa análise econômica, comparando os custos da fabricação ou da execução de determinada operação com o custo de aquisição de um parceiro terceirizado (GUTWALD, 1996). Isso deve refletir em custos menores para o comprador, derivados de uma melhora nos processos e na redução de encargos trabalhistas. Também são considerados os custos de transação, o que vem ao encontro de Williamson (2000), o qual indica que essa avaliação ocorre quando um bem ou um serviço é transferido para uma interface tecnologicamente separada. Os custos de transação são aqueles ocorridos quando os agentes dispostos a efetivar a transação, comunicam-se e trocam informações, que não se resumem ao preço.

Outra motivação para contratar um terceirizado, vincula-se à importância estratégica de a empresa concentrar-se na sua atividade foco, deixando para terceiros as atividades de apoio e que não estejam relacionadas com sua competência essencial, o que segundo Prahalad e Hamel (1990), proporciona vantagem competitiva, por vir a ser uma solução encontrada pelos gestores que pode reduzir custos e garantir qualidade e confiabilidade dos processos. Nessa mesma linha, Tallon (2008) indica que a terceirização ocorre no momento em que as organizações buscam um especialista em determinada atividade, evitando a realização de investimentos e aquisição de know-how, que dependem de uma especialização que não é sua core competence.

As competências essenciais envolvem, frequentemente, tarefas avançadas ou baseadas no conhecimento que separam as empresas dos concorrentes (BOLUMOLE, 2003; JENSEN; PEDERSEN, 2012), podendo incluir produção intensiva de competências, construção de relacionamento com clientes, inteligência de mercado e integração de sistemas (EDVARDSSON, 2011; YU; LINDSAY, 2011; DIAZ-MORA; TRIGUERO-CANO, 2012; JENSEN; PEDERSEN, 2012). As organizações podem, portanto, aumentar o valor que elas oferecem ao derrubar atividades que não suportam essas competências (FILL; VISSER, 2000; HSIAO et al., 2010; ZACHARIA; SANDERS; NIX, 2011). A terceirização permite que as organizações concentrem mais atenção e recursos em sua core competence, ao transferir a provedores externos outras atividades (MUKHERJI; RAMACHANDRAN, 2007; NAYAK; SINHA; GUIN, 2007; JENSEN; PEDERSEN, 2012).

Segundo Delgado (2013), na terceirização, dissocia-se a relação econômica de trabalho da relação jurídico-trabalhista que lhe seria correspondente ao inserir o trabalhador no processo produtivo do tomador de serviços sem que se estendam a esse os laços jurídicos e trabalhistas, que se preservam fixados com uma entidade interveniente. Dessa forma, surge por meio da terceirização, uma relação trilateral entre o prestador de serviço, que realiza suas atividades materiais e intelectuais na empresa tomadora de serviços, a empresa terceirizada que contrata o empregado e assume com ele os vínculos jurídico-trabalhistas pertinentes; a empresa tomadora de serviços que recebe a prestação de labor, mas não assume a posição clássica de empregadora desse trabalhador envolvido, o que diminui custos e riscos trabalhistas. 
Os pesquisados apontam a importância da especialização na atividade a ser terceirizada por parte do fornecedor, o que ocorre por meio da gestão conjunta de custos e processos, associados a culturas semelhantes e ao desenvolvimento conjunto de inovações e processos, como elementos de diferenciação entre fornecedores (Quadro 2). A diferenciação também depende de um baixo turnover, visto que as pessoas precisam se incorporar à cultura e aos processos dos clientes. Nesse momento, surge a principal contribuição teórica-empírica do estudo para a temática do outsourcing, que é a forma de um fornecedor diferenciar sua oferta, e, por consequência, o que pode levar à sua contratação.

Para alcançar os diferenciais indicados, é preciso a adoção de uma abordagem relacional e em longo prazo entre as partes envolvidas, característica de mercados B2B. Isso remete ao valor da relação instituída entre comprador e fornecedor quando ocorre a terceirização, o que permite o relacionamento e o envolvimento das organizações com culturas, experiências, estilos de gestão e competências distintas (BIDAULT; CUMMINGS, 1994). Entre as vantagens dessa abordagem relacional, está o desenvolvimento de know-how, importante fonte de inovação e mudança e a possibilidade dos parceiros fazerem benchmarking, tomando contato com best practices, as quais oportunizam identificar competências e aprimorar modelos de gestão (COSTA; BARREIROS, 2013). Relacionamentos coesos podem aprimorar o desenvolvimento de novos processos e tecnologias e agregar valor aos clientes dos compradores de serviços terceirizados, graças à redução de custos e ao aumento da flexibilidade necessária para competir num ambiente com concorrência crescente, aos ciclos de produção mais curtos, à orientação para o cliente e à busca por custos cada vez menores (BUSI; MCIVOR; 2008; PATIL; PATIL, 2014).

O relacionamento, característica dos mercados B2B (HADJIKHANI; LAPLACA, 2013), remete à interdependência, a qual pode atenuar a falta de profissionalização e a baixa qualidade dos fornecedores de serviços terceirizados, uma vez que permite alta adaptação à cultura e a processos do cliente. Essa falta de qualidade nos serviços terceirizados, foi citada pelos entrevistados como um problema dos ofertantes, que remete a necessidade do fornecedor "entrar na cultura e processos, se sincronizar melhor com as demandas dos seus clientes", o que perpassa por uma abordagem de negócio relacional e não transacional. A adoção do marketing de relacionamento por parte dos fornecedores no mercado de terceirização permite um esforço integrado que objetiva identificar, construir e manter uma rede de relacionamentos, trazendo ganhos mútuos, duradouros e em longo prazo (GUMMESSON, 2002), o que irá compensar o investimento no relacionamento e por consequência na terceirização.

Ao se desenvolver um processo de relacionamento, a chance de fidelizar o cliente é maior, o que depende de informações sobre a cultura, os processos e as demandas do mercado do cliente, aspectos destacados na pesquisa desenvolvida. O fornecedor passa a compreender o cliente, e essa abordagem gera mais benefícios que a redução de custos, pois a empresa fornecedora ganha o status de fornecedor-chave (ULAGA; EGGERT, 2006), o que é sustentado por construtos emocionais, os quais incluem histórias compartilhadas, crenças centrais, objetivos, senso de comprometimento, dependência, auxílio social, intimidade, interesse, respeito e confiança.

Considerando o que foi expressado e evidenciado pelos entrevistados, deve-se construir uma estratégia de relacionamento para diferenciar os fornecedores desse mercado e, para tanto, é imperativo promover o compartilhamento de informações, o qual está 
inserido na dimensão do valor do conhecimento, no conceito de value relationship. Isso é construído pela abertura de canais de comunicação que melhoram o compartilhamento de informações entre os parceiros, gerando inteligência de mercado por meio de informações que uma das partes fornece sobre o mercado à outra, acrescido por ideias discutidas em conjunto para a inovação (BIGGEMANN; BUTTLE, 2012).

Não obstante, não deve-se esquecer da importância dos benefícios econômicos e estratégicos da terceirização para os compradores, bem como da necessidade de o fornecedor atender às demandas legais e ter as certificações exigidas para atuar nesse mercado. Tais aspectos são essenciais, juntamente com o baixo turnover de colaboradores para entrar nesse jogo competitivo, contudo, não basta entrar nessa arena, mas os fornecedores devem buscar a diferenciação, o que perpassa pelo relacionamento e que vem de encontro a uma visão puramente econômica e transacional como forma de competição no mercado de outsourcing.

\section{CONSIDERAÇÕES FINAIS}

A partir do estudo, foi possível inferir os seguintes achados: (i) o principal motivo para a terceirização é o menor custo de operacionalização das atividades das empresas; (ii) a gestão do relacionamento é um fator determinante da diferenciação entre os fornecedores.

No momento que se amplia a discussão sobre o processo de compra nesse mercado B2B, o estudo contribui ao destacar a importância do relacionamento entre fornecedores e compradores, demonstrando que os critérios tradicionais (análise econômica, análise de competências essenciais e análise dos custos de transação) são insuficientes para a escolha de um fornecedor de outsourcing no mercado estudado e que não garantem a diferenciação entre os competidores (JUNIOR; PINHEIRO; DIAS, 2011; BREWER; ASHENBAUM; OGDEN, 2013). A diferenciação depende da profissionalização e da especialização da empresa contratada, assim como do desenvolvimento de processos inovadores configurados pela criação de parcerias, e, consequentemente, sustentados pelo relacionamento de longo prazo, o que indica o papel fundamental do marketing de relacionamento para a construção de uma estratégia de diferenciação. Dessa forma, trocas relacionais de sucesso remetem a ganhos mútuos, ou seja, duradouros em longo prazo, os quais compensam os investimentos no relacionamento (GUMMESSON; 2002). Ainda, ao compartilhar uma gestão conjunta de processos e custos, somados ao alinhamento cultural com o cliente, o fornecedor de outsourcing ingressa num processo de confiança mútua, a qual torna-se ao natural um dos principais sustentáculos do relacionamento, por meio do compartilhamento de valores e da cultura das organizações, o que potencializa a capacidade de resolução de problemas e customização das ofertas por parte dos seus clientes (SCHILKE; LUMINEAU, 2016; BERTRAND; LUMINEAU, 2016; MCEVILY; ZAHEER; KAMAL, 2017; GUMMESSON, 2017).

Numa perspectiva gerencial, os fornecedores que atuam no mercado de outsourcing no agronegócio podem se apropriar do conhecimento gerado para desenvolver estratégias e definir suas operações e ações comerciais, considerando a necessidade de abordar o comprador, numa perspectiva relacional, seja na pré-transação, na transação e na póstransação, que são etapas a serem consideradas para a construção de programas de marketing de relacionamento.

O estudo tem suas limitações no que se refere à generalização dos resultados por ter uma abordagem qualitativa, mas, ao mesmo tempo, abre espaço para pesquisar as dimensões identificadas, apontando algumas possibilidades específicas de estudos futuros, entre as quais

RGO REVISTA GESTÃO ORGANIZACIONAL | VOL. 11 - № 3 - SET./DEZ. - 2018 
a realização de estudos quantitativos que verifiquem quais das dimensões identificadas melhor explicam o processo de relacionamento no mercado e objeto estudado. Ainda, podese abordar de forma diferenciada o desenho da pesquisa e a validação empírica, explorando o modelo de aceitação da terceirização baseado no Technology Acceptance Model (TAM) proposto por Benamati e Rajkumar (2003). Finalmente, Marshall, Mcivor e Lamming (2015) em seus estudos citam que a literatura existente sobre os quadros de terceirização, que são dominados pela perspectiva racional, poderiam integrar as construções políticas para fornecer uma visão abrangente da terceirização fundamentada na realidade organizacional (VINING; GLOBERMAN, 1999; INSINGA; WERLE, 2000; MCIVOR et. al., 2009).

\section{REFERÊNCIAS}

AGOSTINI, L.; NOSELLA, A. Inter-organizational relationships involving SMEs: a bibliographic investigation into the state of the art. Long Range Planning, p.1-31, 2018. No prelo.

ARIAS-ARANDA, D.; BUSTINZA, O. F.; BARRALES-MOLINA, V. Operations flexibility and outsourcing benefits: an empirical study in service firms. The Service Industries Journal, v. 31, n. 11, p. 1849-1870, 2010.

BARROS, A. M. Curso de direito do trabalho. São Paulo: LTr Editora, 2006.

BENAMATI, J.; RAJKUMAR, T. An empirical study of the applicability of the technology acceptance model to application development outsourcing decisions. AIS Electronic Library (AISeL), AMCIS Proceeding, p.1594-1606, 2003.

BERTRAND, O.; LUMINEAU, F. Partners in crime: The effects of diversity on the longevity of cartels. Academy of Management Journal, v. 59, n. 3, p. 983-1008, 2016.

BIDAULT, F.; CUMMINGS, F. Innovating through alliances: expectations and limitations. R\&D Management, v. 24, n. 1, p. 33-45, 1994.

BIGGEMANN, S.; BUTTLE, F. Intrinsic value of business-to-business relationships: an empirical taxonomy. Journal of Business Research, v. 65, n. 8, p. 1132-1138, 2012.

BOLUMOLE, Y. A. Evaluating the supply chain role of logistics service providers. International Journal of Logistics Management, v. 14, n. 2, p. 93-107, 2003.

BUSI, M.; MCIVOR, R. Setting the outsourcing research agenda: the top-10 most urgent outsourcing areas. Strategic Outsourcing: An International Journal, v. 1, n. 3, p. 185-197, 2008.

BREWER, B.; ASHENBAUM, B.; OGDEN, J. A. Connecting strategy-linked outsourcing approaches and expected performance. International Journal of Physical Distribution \& Logistics Management, v. 43, n. 3, p.176-204, 2013. 
BRITO, E. P. Z.; MARITTO, G. Benefits of cooperation between buyers and providers: a study in the field of information and communications technology. Revista Brasileira de Gestão de Negócios, v.15, n. 47, p. 241-261, 2013.

BROWN et al.What factors influence buying center brand sensitivity? Industrial Marketing Management, v. 41, n 1, p. 508-520, 2012.

CHANG, S.-H.; WANG, K-Y., CHIH, W-H. Building customer commitment in business-tobusiness markets. Industrial Marketing Management, v. 41, n. 6, p. 940-950, 2012.

CHOPRA, S.; MEINDL, P. Gerenciamento da cadeia de suprimentos. 1 ed. São Paulo: Pearson, 2002.

COASE, R. H. The nature of the firm. Economica. New Series, v. 4, n. 16, 386-405, 1937.

COSTA R. L.; BARREIROS, L. O outsourcing dos serviços como recurso estratégico de competitividade internacional da economia portuguesa. Revista Gestão e Planejamento, v.14, n. 2, p. 215-231, 2013.

DELGADO, M. G. Curso de direito do trabalho. 12 ed. São Paulo: LTr, 2013.

DIAZ-MORA, C.; TRIGUERO-CANO, A. Why do some firms contract out production? Evidence from firm-level panel data. Applied Economics, v. 44, n. 13, p. 1631-1644, 2012.

EDVARDSSON, I. R. The impact of outsourcing strategies on companies' intellectual property. Knowledge Management Research \& Practice, v. 9, p. 286-292, 2011.

ELMUTI, D.; KATHAWALA, Y.; MONIPPALLIL, M. Outsourcing to gain competitive advantage. Industrial Management, v. 40, n. 3, p. 20-24, 1998.

ENSSLIN et al. It outsourcing management: the state of the art recognition by a constructivist research process and bibliometrics. Journal of Information Systems and Technology Management, v. 12, n. 2, p. 371-392, 2015.

FAGUNDES, J. Economia Institucional: Custos de Transação e Impactos sobre Política de Defesa da Concorrência. Texto para Discussão, Grupo de Regulação da concorrência, número 407, IE/UFRJ, (1997).

FERRUZZI et al. Reasons for outsourcing services in medium and large companies. Brazilian Business Review, v. 8, n. 4, p. 44-66, 2011.

FILL, C.; VISSER, E. The outsourcing dilemma: a composite approach to the make or buy decision. Management Decision. v. 38, n.1, p. 43-50, 2000. 
GEIGER et al. The bonding effects of relationship value and switching costs in industrial buyer-seller relationships: An investigation into role differences. Industrial Marketing Management, v. 41, n. 1, p. 82-93, 2012.

GIL, A. C. Como elaborar projetos de pesquisa. 5 ed. São Paulo: Atlas, 2010.

GUARNIERI, P.; ALMEIDA, A. T. Framework to Manage Suppliers for Strategic Alliances with a Multicriteria Method. Production, v. 25, n. 3, p. 713-724, 2015.

GULATI, R.; NICKERSON, J. A. Interorganizational trust, governance choice, and exchange performance. Organization Science, v. 19, p. 688-708, 2008.

GUMMESSON, E. Relationship Marketing in the New Economy. Journal of Relationship Marketing, v. 1, n. 1, p. 37-57, 2002.

GUMMESSON, E. From relationship marketing to total relationship marketing and beyond. Journal of Services Marketing, v. 3, n. 1, p. 16-19, 2017.

GUTWALD, P. M. Strategic Sourcing and Technology Supply-Chains. 1996, 93 f. Master's thesis (Master of Science in Management)-Massachusetts Institute of Technology, Massachusetts, 1996.

GRÖNROOS, C.; GRÖNROOS, C. Internationalization strategies for services: a retrospective. Journal of Services Marketing. v. 30, n. 2, p.129-132, 2016

HADIIKHANI, A., LAPLACA, P. Development of B2B marketing theory. Industrial Marketing Management, v. 42, n. 3, p. 294-305, 2013.

HÅKANSSON, H.; SNEHOTA, I. The Significance of Business Relationships (eds). No Business is an Island, p. 1-25, 2017.

HÄTÖNEN, J.; ERIKSSON, T. 30+ years of research and practice of outsourcing - Exploring the past and anticipating the future. Journal of International Management, v.15, n.2, p. 142155, 2009.

HUANG, X.; CHINA, B. A research on development mode innovation of the large logistics enterprises in publishing industry. Beijing: IEEE, 2014.

HSIAO et al. Developing a decision-making framework for levels of logistics outsourcing in food supply chain networks. International Journal of Physical Distribution \& Logistics Management, v. 40, n. 5, p. 395-414, 2010.

INSINGA, R. C.; WERLE, M. J. Linking outsourcing to business strategy. Academy of Management Executive, v. 14, n. 4, p. 58-70, 2000. 
IPEA- INSTITUTO DE PESQUISA ECONÔMICA APLICADA. Terceirização no Brasil: avaliação do marco legal e esclarecimentos sobre o projeto de lei no 4.330/20041. Ministério do Planejamento, Orçamento e Gestão: Brasília: Ipea, 2015.

JENSEN, P. D. O.; PEDERSEN, T. Offshoring and international competitiveness: antecedents of offshoring advanced tasks. Journal of the Academy of Marketing Science, v. 40, p. 313328, 2012.

JUNIOR, J. M.; PINHEIRO, P. R. L., DIAS, G. A. Aceitação do outsourcing enquanto estratégia de gestão do conhecimento. In: ASSOCIAÇÃO NACIONAL DE PÓS-

GRADUAÇÃO E PESQUISA EM ADMINISTRAÇÃO - ANPAD, 35., 2011, Rio de Janeiro. Anais eletrônicos... Rio de Janeiro: ANPAD, 2011. Disponível em: <

http://www.anpad.org.br/admin/pdf/ADI1313.pdf >. Acesso em: 26 abr. 2018.

KANG, M.; WU, X., HONG, P. Strategic outsourcing practices of multi-national corporations (MNCs) in China. Strategic Outsourcing: An International Journal, v. 2, n. 3, p. 240-256, 2009.

KOTABE et al. PARENTE, R. Outsourcing and its implications for market success: negative curvilinearity, firm resources, and competition. Journal of the Academy of Marketing Science, v. 40, p. 329-346, 2012.

KUMAR, S.; KOPITZKE, K. K. A practitioner's decision model for the total cost of outsourcing and application to China, Mexico, and the United States. Journal of Business Logistics, v. 29, n. 2, p. 107-139, 2008.

KROES, J. R.; GHOSH, S. Outsourcing congruence with competitive priorities: impact on supply chain and firm performance. Journal of Operations Management, v. 28, p. 124-143, 2010.

LACITY, M. C.; KHAN, S. A.; WILLCOCKS, L. P. Uma revisão da literatura de terceirização de TI: Insights para a prática. O Journal of Strategic Information Systems, v.18, n. 3, p. 130-146, 2009.

LEONIDOU et al. International Marketing Research: A State-of-the-Art Review and the Way Forward. Advances in Global Marketing. Springer, p. 3-33, 2018. Disponível em: https://link.springer.com/chapter/10.1007/978-3-319-61385-7_1\#citeas. Acesso em: 30 out. 2018.

MCEVILY, B.; ZAHEER, A.; KAMAL, D. K. F. Mutual and exclusive: Dyadic sources of trust in interorganizational exchange. Organization Science, v. 28, n. 1, p. 74-92, 2017. 
MCIVOR, R.; HUMPHREYS, P.; MCKITTRICK, A.; WALL, T. Performance management and the outsourcing process: lessons from a financial services organization. International Journal of Operations \& Production Management, v. 29, n.10, p. 1025-1048, 2009.

MACNEIL, I. The new social contract, an inquiry into modern contractual relations. New Haven: Yale University Press, 1980.

MALHOTRA, N. K. Pesquisa de Marketing: uma orientação aplicada. 3 ed. Porto Alegre: Bookman, 2001.

MARSHALL, D.; MCIVOR R.; LAMMING, R. Self-interest or the greater good: how political and rational dynamics influence the outsourcing process. International Journal of Operations \& Production Management, v. 35, n. 4, 2015.

MIRAGLIA, M. M. L. A terceirização trabalhista no brasil. ed. 5. São Paulo: Quartier Latin, 2008.

MUKHERJI, S.; RAMACHANDRAN, J. Outsourcing: practice in search of theory. IIMB Management Review, v. 19, n. 2, p. 103-110, 2007.

NAYAK, J. K.; SINHA, G.; GUIN, K. K. The determinants and impact of outsourcing on small and medium enterprises - an empirical study. IIMB Management Review, v. 19. n. 3, p. 277284, 2007.

NGWENYAMA, O. K.; BRYSON, N. Making the information systems outsourcing decision: a transaction cost approach to analyzing outsourcing decision problems. European Journal of Operational Research, v. 115, p.351-367, 1999.

OSHRI, I.; RAVISHANKAR, M. M. On the attractiveness of the UK for outsourcing services. Strategic Outsourcing: An International Journal, v. 7, n. 1, p. 18-46, 2014.

PANDA, A. K. Business process outsourcing: a strategic review on Indian perspective.

Business Process Management Journal, v. 18, n. 6, p. 876-897, 2012.

PATIL, S.; PATIL, Y. S. A review on outsourcing with a special reference to telecom Operations. Procedia - Social and Behavioral Sciences, v. 133, n. 5, p. 400-416, 2014.

PETERSON, R. A. Relationship Marketing and the Consumer. Journal of Marketing, v. 23, n. 4, p. 278-281, 1995.

PFEFFER, J.; SALANSICK, G. R. The external control of organizations: A resource dependence perspective. Stanford University Press, 2003. 
PLUGGE, A.; BOUWMAN, H., MOLINA-CASTILLO, F. J. Outsourcing capabilities, organizational structure and performance quality monitoring: Toward a fit model. Information \& Management, v. 50, n. 1, p. 275-284, 2013.

PONDÉ, J. L.; FAGUNDES, J.; POSSAS, M. Custos de Transação Política de Defesa da Concorrência. Revista de Economia Contemporânea, n.1, v.2, p.115-135, 1997.

PRADO, V. P. E. Terceirização de serviço de TIC: uma avaliação sob o ponto de vista do fornecedor. Revista Eletrônica de Administração, v. 15, n. 3, p. 653-678, 2009.

PRAHALAD, C. K.; HAMEL, G. The Core Competence of the Corporation. Harvard Business Review, May/June, 1990.

PRESUTTI et al. Distance to customers, absorptive capacity, and innovation in high-tech firms: the dark face of geographical proximity. Journal of Small Business Management, 2017.

ROESCH, S. M. A. Projetos de estágio e de pesquisa em administração. 3 ed. São Paulo: Atlas, 2005.

ROUSSEAU, D. M. Psychological and implied contracts in organizations. Employee Responsibilities and Rights Journal, v. 2, p. 121-139, 1989.

SANDERS et al. A multidimensional framework for understanding outsourcing arrangements. Journal of Supply Chain Management, v. 43, n. 4, p. 3-15, 2007.

SCHILKE O.; LUMINEAU F. The double-edged effect of contracts on alliance performance. Journal of Management, p.1-32, 2016.

SCHUTT, R. K. Investigating the social world: the process and practice of research. Sage Publications, p. 1-595, 2012.

SWEENEY, J.; WEBB, D. Relationship Benefits: an exploration of buyer-supplier dyads. Journal of Relationship Marketing, v.1, n. 2, 77-91, 2002.

TALLON, P. Inside the adaptive enterprise: an information technology capabilities perspective on business process agility. Information Technology Management, v. 9, n. 1, p. 21-36, 2008.

ULAGA, W.; EGGERT, A. Value-based differentiation in business relationships: gaining and sustaining key supplier status. Journal of Marketing, v.70, n. 1, p. 119-136, 2006.

VIANA, F. L. E.; BARROS N. J. P.; AÑEZ, M. E. M. Gestão da cadeia de suprimento e vantagem competitiva relacional nas indústrias têxtil e de calçados. Gestão \& Produção, v. 21, n. 4, p. 836-852, 2014. 
VINING, A.; GLOBERMAN, S. A conceptual framework for understanding the outsourcing decision. European Management Journal, v. 17, n. 6, p. 645-654, 1999.

WEIGELT, C.; SAKAR, M. B. Performance implications of outsourcing for technology innovations: managing the efficiency and adaptability trade-off. Strategic Management Journal, v. 33, n. 2, p. 189-21, 2012.

WILLIAMSON, O. E. The economic institutions of capitalism: firms, markets, relational contracting. New York: Free Press, 1985.

WILLIAMSON, O. E. The new institutional economics: taking stock, looking ahead. Journal of Economic Literature, v. 38, n. 2, p. 595 - 613, 2000.

YU, Y.; LINDSAY, V. Operational effects and firms' responses: perspectives of New Zealand apparel firms on international outsourcing. International Journal of Logistics Management, v. 22, n. 3, p. 306-323, 2011.

ZACHARIA, Z. G.; SANDERS, N. R.; NIX, N. W. The emerging role of the third-party logistics provider (3PL) as an orchestrator. Journal of Business Logistics, v. 32, n. 1, p. 4054, 2011.

ZAHEER, A.; J. HARRIS. Interorganizational trust. In: SHENKAR, O., REUER, J. Handbook of strategic alliances. Sage Publications, p. 169-197, 2005. 